\title{
Lecturer Perceptions of General Education in Enhancing Self-Efficacy of Accounting Students
}

\author{
S.K. Naidoo ${ }^{1} \&$ S. Govender ${ }^{2}$ \\ ${ }^{1}$ Department of Management Accounting, Durban University of Technology, South Africa \\ 2External Research Supervisor, Durban University of Technology, South Africa \\ naidoos@dut.ac.za,dr1govender@telkomsa.net
}

\begin{abstract}
The research paper aims to obtain the perceptions of lecturers on the influence of General Education in enhancing the Self-efficacy of accounting learners. Interviews with lecturers from Durban University of Technology (DUT) and Mangosuthu University of Technology (MUT) were conducted to tap into their views on the aspect of General Education and establish any impact on learners' Self-efficacy. The researcher has observed, over many years of lecturing experience at the university that some learners are eager to learn and can address new tasks, while others appear uninterested or unmotivated. Many learners display a high degree of faith in their skills, while others appear uncertain of themselves. The question then arises: What strategies can a classroom teacher or lecturer use to increase learners' confidence to learn new material? There is an opportunity for the improvement of General Education skills that can enhance learner performance. Hence, the main strategy would be to incorporate General Education Modules into the curriculum. Similar to General Education skills, there is also a lack of Self-efficacy in current learners. Further attention must be devoted to General Education skills, as these are essential. Moreover, these skills appear to be very poor amongst current learners and respondents believed that Self-efficacy could have a positive effect on the academic performance of learners. Methods for enhancing Self-efficacy reveal that the main strategies should revolve around innovative teaching, learning and research methods; increasing skills development such as critical thinking and computer skills; and promoting more Self-efficacy based workshops and programs.
\end{abstract}

Keywords: Financial Accounting, Critical Thinking Skills, General Education Skills, Management Accounting, Self-efficacy.

\section{Introduction}

The Department of Basic Education (2014: 109) indicated that the level of pass achieved by learners in Mathematics increased between the years 2011 and 2013. There was also a sharp drop in the pass rate in 2014. The percentage of those candidates who passed Mathematics at 40 percent increased from 30.1 percent to 40.5 percent between the years 2011 and 2013. There was also a decrease in the year 2014 to 35.1 percent for candidates who passed Mathematics at 40 percent. Moreover, there was a decrease in the number of candidates writing Mathematics from 241509 in 2013 to 225458 in 2014. The 5.4 percent drop in candidates who passed Mathematics at 40 percent and the declining number of 16051 learners writing Mathematics 2014 remains a great concern. Similar scenarios persisted in Mathematical Literacy. Taylor, Van der Berg and Mabogoane (2012: 20) suggested that grade 6 language teachers did not score well on the SACMEQ reading exam. NEEDU (2013) notes the most striking aspect as that being $72 \%$ of the three best learners in each class studied were reading below the average grade 2 student benchmark and $22 \%$ were on or below the weak level.

Ramos (2010: 31) postulates that reading strategies and writing skills have a strong connection. Such results show that reading strategies are valuable predictors of writing abilities. The University of Central Arkansas (2018) indicates that General Education has six skills areas. These focus areas are: (i) Written Communication; (ii) Critical Thinking; (iii) Oral Communication; (iv) Information Technology; and (v) Quantitative Analysis and Researching. According to Greer (2012), General Education helps learners to achieve a synthesis of oral and written communication, physical and natural sciences, humanities, arts and social sciences, fitness and wellness skills, comprehension and knowledge. It is a comprehensive collection of learning experiences organized through subject disciplines to provide the requisite skills and information to work in society. Washington State University (2019) notes that General Education is important to operate well in the workforce and it promotes the incorporation of the planned careers of learners in wider, more inclusive and multiple contexts. Exposure to the different beliefs, viewpoints and cultural practices is valuable 
training for the kinds of work that college graduates do. This experience will greatly enrich their understanding of the context and significance of careers.

Siegle (2000) defines Self-efficacy as a judgment of an individual on being able to perform a particular task. Self-efficacy refers to the "I can" or "I can't" creed of a learner. Self-efficacy and self-esteem are distinct. Siegle (2000) claims that, unlike self-esteem which represents how learners feel about their worth or importance, Self-efficacy represents how positive learners are about particular tasks being carried out. The researcher also posits that Self-efficacy is unique to the task being attempted and that high Self-efficacy in one field does not correlate with high Self-efficacy in another. For example, high swimming confidence would not equal high baseball confidence or high Mathematics Self-efficacy does not naturally follow high spelling Self-efficacy, for comparative purposes. It has been found that Self-efficacy beliefs have certain shifts in the success sense of a student, interfere with self-regulated learning processes and arbitrate the academic achievement of learners (Zimmerman 2000). Self-efficacy is an important motivational concept, which according to Gist and Mitchell (1992) affects individual decisions, goals, emotional responses, commitment, coping and resilience. The authors further argue that Self-efficacy changes because of learning, experience and feedback. The construct of Self-efficacy has received increasing empirical attention in the organizational behavior literature.

Gist and Mitchell (1992) claim that it is easier for people who believe they will do well on a mission than for those who believe they will fail. Improvements in Self-efficacy are correlated with bona fide improvements in the level of skills. However, additional understanding of efficacy arises through shifts in temperament, motivation, and the mission itself. General Education will empower learners to be more self-reliant while studying. Zimmerman (2000) argues that Self-efficacy has proven to be sensitive to changes in learning methods especially those involving greater self-regulation and predictive outcomes of achievement. The research paper envisages that the Self-efficacy level of learners who undertake the General Education Modules will be higher than before the introduction of the modules. General Education will enable the student to have more confidence in themselves when dealing with quantitative analysis, problem-solving; critical and creative thinking; written and oral communication; information and technological literacy; teamwork and ethical deliberation, enabling them to be more successful in the Accounting environment. The findings from the interviews will establish the degree of the relationship between the General Education Modules and Self-efficacy and the influence thereof on the academic performance of accounting learners. The findings will positively contribute to the university's learner pass rate and ultimately government funding.

\section{Literature Review}

Socio-Economic Status: The present section addresses issues regarding socio-economic challenges experienced by many learners and the impact thereof on their quality of education. It also addresses the link between the socio-economic status of students and education; the significance of socioeconomic status for higher learning; and the characteristics of better functioning schools. The section includes an overview of the socio-economic status of other African countries.

Overview of Socio-Economic Status: Corrigan (2009) of the South African Institute of International Affairs points out that socio-economic development issues have been identified in six African countries that have received Country Evaluation Reports from the African Peer Review System (APRM), namely Ghana, Rwanda, Kenya, Algeria, Benin and South Africa. All these countries have gone through difficult phases in the relatively recent past. Corrigan (2009) states that the APRM Country Evaluation Report indicates that inequality, land access, inadequate education systems, gender discrimination and poor healthcare systems are common problems amongst these countries. In an article titled 'How does socio-economic status impact on educational outcomes in South Africa?', the University of South Africa (UNISA) (2012) reports that an independent researcher indicated that nearly $75 \%$ of all South African children are trapped in poverty and the lack of financial and social capital causes them to go to poorly performing schools.

Socio-Economic Status and Education Relationship: The standard and quality of education that an individual receives is a contributing factor to the number of prospects that are available to the individual. The increase in educated individuals will contribute positively to higher levels of labor development. Education is a key factor in a country's socio-economic advancement and plays a key role in developing human capabilities 
and speeding up economic growth through a society's awareness, abilities and innovative power (Kiani 2015). Kiani (2015) also believes that the positive effects of education include declining poverty and inequality, improving health status and good governance in socio-economic policy implementation. The lack of meaningful schooling and urban representation in committee membership and office holding leads to reduced involvement in growth programs at the advanced levels (Imoh, Nwachukwu and U-James 2009). Wall, Pettibone and Kelsey (2005) postulate that socio-economic standing has a substantial influence on a person's level of involvement related to community engagement, as well as a person's education standards and income. Angba, Adesope and Aboh (2009) highlight that as a person attains a higher education standard, the attitude of the person towards involvement in community development is likely to increase constructively. Oladipo and Adekunle (2010) believe that people with high educational achievement are generally fast to adopt innovation and that there is a positive connection between both the standard of education and people's cultural-economic position in society. With the cost of a four-year tertiary education increasing rapidly, affordability has become a major obstacle for equally intelligent and deserving learners.

Higher education has provided sufficient proof of its viability over time and of its capacity to adapt and bring about change and development in society. Society has increasingly become more knowledge-based because of the scale and pace of change so that higher learning and science now serve as critical components of individuals', societies' and nations' political, socio-economic and environmentally sustainable growth (UNESCO 1998b: para. 3 line 1). The most essential part of the debate involves study quality and whether or not this works adequately for the various inputs that might complicate the interpretation of resources. Taylor and $\mathrm{Yu}$ (2009) argue that people with higher educational accomplishment and high socioeconomic status are much more inclined to become active in the school group, thus expanding the sense of duty of the school staff towards the parents and contributing positively to the school standard. Several other studies have also shown that parents with a good education history may have a detrimental impact on the education of their children. For example, the statistical models may not adequately account for other inputs that affect student achievement such as the nature of family inputs. The estimates may then erroneously assign the higher student achievement because of better family aspects as compared to some of the school characteristics (Hanushek and Woessman 2007).

Socio-Economic Status on Higher Learning: According to Landy (2012), for high school students who score in the top $25^{\text {th }}$ percentile on standardized tests, the socio-economic background remains the most important indicator of whether they will go on to achieve college graduation. Landy (2012) points out that high-scoring learners from a poor socio-economic background, according to the 2010 Century Foundation survey, were only around 50 percent likely to attend a four-year college as their wealthier peers, but five times more likely to attend no college at all. Landy (2012) notes that the research conducted by the company found that 74 percent of students in highly selective colleges come from the wealthiest socio-economic market, while only three percent come from the bottom fourth. Data from the United States Department of Education indicate that learners who score in the top 25 percent on standardized tests do not have equal opportunities to pursue secondary education (Landy 2012). The author further states that data indicate that learners from rich socioeconomic backgrounds are more than 80 percent more likely to attend a four-year college program than their peers from a poor socio-economic background. Learners from a poor socio-economic background are five times more likely to experience no college at all, as shown in Figure 1 on socio-economic status. Landy (2012) believes that it is socio-economic factors and not the wealthiest learners that dominate selective colleges simply because they are the smartest. 


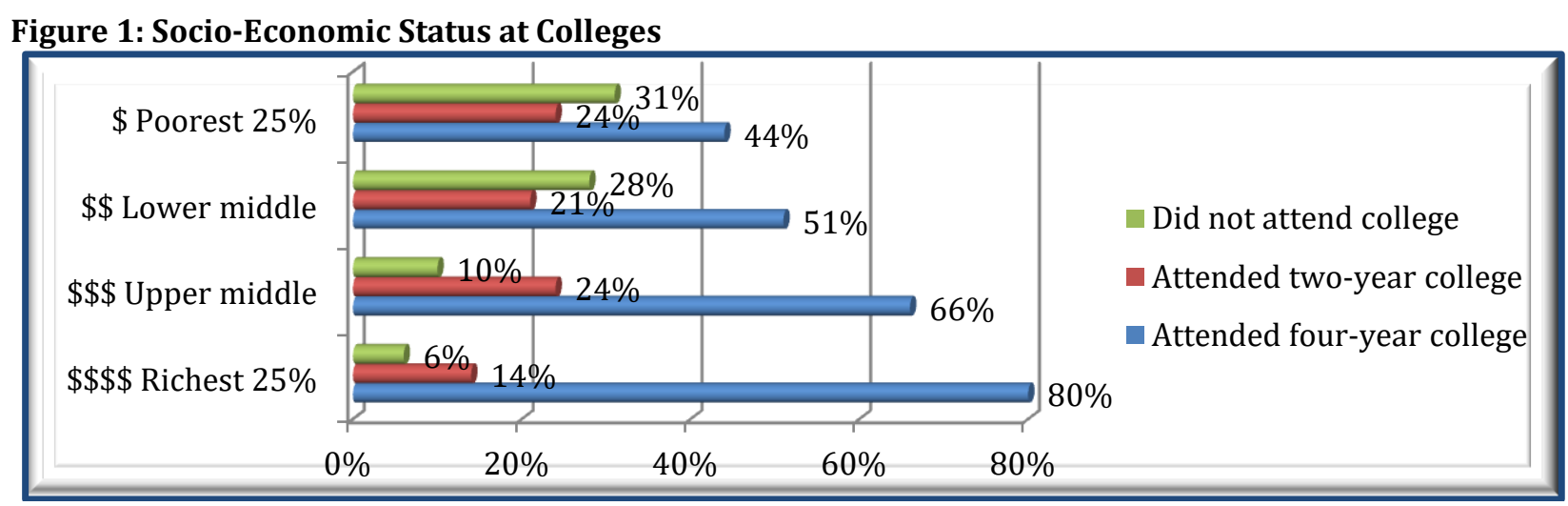

Source: Landy (2012). Adapted.

Analysis of Socio-Economic Status: When learners start discovering drawbacks in educational opportunities, they may expose a collection of shortcomings, such as failure to engage in community development, programs. A greater literacy level is also one of the key contributing factors to favorable attitudes towards involvement in developmental programs. The quality of a country's education system plays a crucial role in providing a way out of poverty. Literacy and numeracy empower learners to participate in society meaningfully. Learners from poor family backgrounds face an educational disadvantage during their schooling, and socioeconomic status in large measure influences educational outcomes, which then, in turn, decide the socio-economic status of the next era. Data from the United States Department of Education indicates that learners who score in the top 25 percent on standardized tests do not have equal opportunities to pursue secondary education and that learners from rich socio-economic backgrounds are more than 80 percent more likely to attend a four-year college program than their peers from a poor socio-economic background. Finally, as some researchers pointed out, the wealthiest learners dominate selective tertiary institutions not because they are simply the most intelligent but socio-economic dynamics also play an important role in the choices of tertiary institutions by parents.

General Education Policy and Procedures of DUT: In an email communication on 05 December 2014, the then Vice-Chancellor of DUT, Professor Ahmed Bawa pointed out that in 2015, the institution will carry out its first experiments with the new General Education curriculum elements. The rollout would take place effectively in 2016 and DUT will have a year to prepare for this launch. According to the then Vice-Chancellor, the rollout was effective in 2016, but the new Management Accounting curriculum only began in 2019. The current study began in 2015 in anticipation that General Education modules will begin in 2016 but the late start of the new curriculum in 2019 has led to a four-year delay in the study. In the same email communication, the Vice-Chancellor also indicated that the new curriculum will be the signature of DUT and would ensure that DUT graduates be provided with a more holistic education curriculum, thereby ensuring that they are not simply trained for the job market but also acquire a more holistic approach to education. The Vice-Chancellor further maintains that the inclusion of the General Education component will change the nature of education within the institution. General Education will be part of a process for the formation of the entire undergraduate program from first to final year and may also be included as stand-alone modules or be embedded within program or faculty modules.

General Education Guidelines: Senate approved curriculum renewal at DUT concerning General Education on 29 August 2012 with the intention of implementation in January 2015. Kift (2008) highlights the importance of developing globally portable people so that they can effectively participate in information generation and management in an increasingly assorted and globalized place of work. For this purpose, curricula and pedagogy design must prepare students for jobs while simultaneously preparing them for vital citizenship in a developing and unstable democracy (DUT 2012: 1). According to DUT (2012: 1), all its graduates after completing the program should be proficient in the following categories:

i. Strong competencies and skills like:

- Literacy of knowledge;

- Oral and written communication; 
- Numerical competence; and

- Technology applications.

ii. Innovation, comprising:

- Entrepreneurship; and

- Management.

iii. Social Responsibility, comprising:

- Multiplicity; and

- Critical and engaged citizenry embedded in a local and global context.

iv. Human Development, comprising:

- Self-awareness; and

- Lifelong and self-directed learning.

v. Wide knowledge of the discipline and/or career they select, as well as:

- Acceptable discipline or technical approach to the development of information; and

- Adaptability to the workplace.

General Education Objectives: DUT (2012: 2) states that the General Educational policy priorities shall be to:

- Create a learner-centered learning environment incorporated into the local context;

- Train students for a dynamic and increasingly competitive global work world; and

- Nurture dedicated and vital citizenship in an evolving and vulnerable democracy in a constantly evolving world system.

General Education Model and Outcomes: Bourke, Bray and Horton (2009) believe that there are three models for the delivery of General Education. The first is the Core Model, which is very restrictive and requires learners to complete a prescribed set of common modules. The second is the Distribution Model, which permits greater learner choice from the different approved categories. The third is the Decentralised Model, where the faculty or department agrees on the General Education requirements for their courses.

General Education Model: According to DUT (2012: 3), the university has a combination of Core, Distribution and Decentralised models.

General Education Outcomes: DUT (2012: 3) highlights that learners can build and improve skills in information, abilities and approaches through their involvement in General Education in the context of their institutional studies through the following:

- Theoretical and practical skills, as well as written and oral communication skills in English, Mathematical and/or quantitative reasoning, analytical and rational analysis and applications of technology;

- A creative and imaginative program;

- Empathy and diversity recognition in a national and global sense;

- Public accountability, as well as physical and moral knowledge and ethical thinking in resolving multifaceted social issues and problems;

- Individual development; and

- Integrative approaches for learning through general and selected fields of study.

General Education Components: The guiding principles for DUT's General Education include the following:

- The General Education section will include 30 percent of the actual overall credits of an undergraduate program and that the 30 percent comprises the following:

$>\quad 10$ percent will be institution-wide and that is external of the home faculty and academic section

$>\quad 10$ percent will be faculty-based

$>\quad 10$ percent will be program-based;

- The management and allocation of credits are to follow the Curriculum Renewal Project requirements from the Centre for Quality Promotion and Assurance. The General Education Modules include at least eight credits and may rise in multiples of four;

- The General Education component will be made up of: 


\section{Mathematics and/or quantitative reasoning}

$>\quad$ Writing-intensive modules

2-4 modules on KZN;

- General Education will be innovative and have an excessive impact on teaching and learning methods, together with:

$>\quad$ community commitment and

$>\quad$ technology in teaching and learning;

- Assessment plans will comprise the measurement of General Education outcomes;

- Assessment plans will provide for the validation of exemptions and Recognition of Prior Learning;

- General Education themes will be associated with the results and graduate aspects;

- A group of General Education optional modules will become accessible for learners to select from;

- A comprehensive structure and a series of both obligatory and/or optional modules are to conclude in capstone learning proficiencies; and

- Permanent academic staff will oversee General Education (DUT 2012: 3).

DUT (2012: 5) highlights that the Cornerstone module will comprise 12 credits and will be compulsory for all DUT first semester undergraduate learners. The cornerstone module will comprise writing, reading, communication, language, quantitative reasoning, technology applications (including online learning/eLearning), human and social sciences.

General Education Themes: DUT (2012: 5) reports that the themes playing a significant role in General Education will include:

- Sustainability of the environment;

- History, politics, economics and philosophy;

- Beliefs and the general public;

- Work readiness;

- Entrepreneurship;

- Personal improvement; and

- Physical condition and wellness.

The above themes will form the basis for the entire undergraduate curriculum from the first to the final year and can be used as stand-alone modules or integrated with program or faculty modules, as well as providing elective modules of eight credits each. A learner must choose from the themes a total of three components for a 3-year program and four components for a 4-year program, for the General Education portion of 10 percent. The modules should be from outside the faculty where the course has been undertaken.

Self-Efficacy Role: Nearly everybody can decide on objectives that they would like to achieve, aspects they would like to improve upon and things they would like to accomplish. Nevertheless, most people do know that it is not as easy as people think to initiate such schemes into effect. Bandura and several others investigated and found that the Self-efficacy of a person plays a critical role in the way to manage goals, tasks and challenges. Bandura and others have researched and found that an individual's Self-efficacy plays a key role as to how to manage goals, tasks and challenges. Cherry (2018) highlights that those learners who have a robust awareness of Self-efficacy:

- Vision thought-provoking difficulties as responsibilities to be grasped;

- Mature a deep sense of the attention in the actions in which they take part;

- Develop a deeper understanding of their desires and behaviors; and

- Make progress speedily from hindrances and displeasures.

Cherry (2018) also believes that those learners with a fragile common sense of Self-efficacy:

- Evade thought-provoking errands;

- Assume that problem activities and circumstances are beyond their ability;

- Concentrate on moral weaknesses and negative consequences; and

- Extremely quickly run the risk of losing trust in personal skills. 
Besides, learners with elevated Self-efficacy tend to absorb and gain beyond persons with little Self-efficacy, even whilst the real skill rates are alike (Ormrod, 2008). The next section explains the sources of Self-efficacy.

Self-Efficacy Sources: In attempting to increase the Self-efficacy of learners, it is firstly important to identify and understand its sources. Cherry (2018) suggests that early childhood Self-efficacy continues to grow as youngsters cope with an extensive range of encounters, activities and circumstances. Nevertheless, Selfefficacy improvement did not necessarily conclude throughout early phases but continues to expand throughout entire lives as people gain new talents, interactions and the ability to understand (Cherry 2018). The sources of Self-efficacy stem from the learner's variety of experiences throughout their life. The primary research focus of Bandura's early work was on the tendency and ability of learners to understand and adjust their actions by vicarious interaction and social modeling, instead of by actual experience.

Bandura (1994) advocates that Self-efficacy beliefs are formed according to how people perceive the feedback they receive from four sources:

i. Past Performance (Bandura claims that one of the most powerful ways to build a clear sense of success would be through interactions of mastery);

ii. Modelled Behaviour;

iii. Social Persuasion or Feedback from others; and

iv. Physiological Responses.

Self-Efficacy Dimension Theory (Management Accounting): Self-efficacy judgments vary on three individual but interconnected dimensions. The measurement of Self-efficacy relates to these interrelated dimensions. The dimensions referred to are magnitude, strength and generalizability. The current section explores the impact of these three dimensions of Self-efficacy on Management Accounting. Management accounting Self-efficacy means assessing the ability to evaluate information correlations and then use historical patterns to forecast and direct business judgments. Management Accounting is concerned with historical data or information and utilizing the information to make judgments of what must transpire in the future. Moreover, it is not about not only simply collecting information or data, but rather includes formulating conclusions; defining and managing risks; evaluating information and using it for business decisions; planning and budgeting (e.g. compiling written statements or reviewing financial information).

Magnitude: The Management Accounting Self-efficacy magnitude can point towards the level of capability expected to work under pressure, working to deadlines, working long hours and heavy responsibilities. Hence, mistakes in the Management Accounting sphere can be very costly to the organization. Therefore, learners with a high magnitude of Self-efficacy in Management Accounting may tend to consider themselves as capable of performing more challenging management tasks compared to those with lower Self-efficacy judgments. Put another way, the magnitude of Self-efficacy in Management Accounting could be determined in terms of the levels of support needed to execute a task. Students with a higher degree of Self-efficacy in Management Accounting could consider themselves confident in functioning independently with less support and guidance than those who have less Self-efficacy judgments.

Generalisability: Self-efficacy generalizability reflects on the degree to which the judgment is limited to a particular domain of activity as indicated by Bandura. Within the Accounting context, these domains may well be considered to reflect analytical, advisory, decision-making and soft skills of trained management accountants. As a result, learners with a high degree of Management Accounting Self-efficacy generalisability will be able to use a wide range of skills competently. The range of skills is namely in Identifying and Managing Risks; Analysing Information (using it to make business decisions); Planning and Budgeting. However, those with low Management Accounting Self-efficacy generalisability would perceive their capabilities as limited to particular aspects of Management Accounting.

Strength: The strength of Management Accounting Self-efficacy judgment relates to the level of trust about the decision, or the confidence that a learner has regarding their ability to perform the various tasks as discussed above. Thus, not only would learners by way of high Management Accounting Self-efficacy perceive themselves as able to accomplish more challenging tasks (high magnitude), but the learners would demonstrate better confidence about their ability to successfully perform each of the activities. 
Self-Efficacy Assessment Processes and Relationship Model: The philosophy of Self-efficacy refers to the classification of four types of variables involved in the production of Self-efficacy: enactive mastery; vicarious experience, verbal persuasion; and physiological excitement. The three assessment methods used to measure Self-efficacy can assess the degree of Self-efficacy that actually affects the outcomes of learners' success.

Assessment Processes: The three Self-efficacy evaluation processes are activity criteria analysis, knowledge attribution analysis and personal and situational resource evaluation. The discussion regarding the three assessment processes together with their association with Self-efficacy follows.

Analysis of Task Requirements: The performance required at different levels will depend on a learner's strength of mind. An analysis of task requirements produces judgments about what it will take to perform at various levels (Gist and Mitchell, 1992). The researchers highlight that when a learner is considering a responsibility of making a market prediction, he/she may acknowledge the degree to which mathematical skills like those of statistics are required to perform well, and the time required. Significantly, a learner attempts to identify and organize the distinctive information clues made available by the four types of experience. Accordingly, the activity analysis should be well described whenever the work is unique or even just discovered. The tasks that were performed personally and frequently by individuals in the past, then those individuals are likely to rely more heavily on their understanding of the causes of earlier performance levels (Gist and Mitchell, 1992).

Attributional Analysis of Experience: Gist and Mitchell (1992) point out that attributional analysis involves a learner's judgment about why such an accomplishment level took place. Even though individual experiences may perhaps make available the robust data for attributional scrutiny, causal information from experiences such as persuasion or modelling can also be gathered (Gist and Mitchell, 1992). The researchers indicate that learners may determine the appropriate skills and personality traits adopted by lecturers or peers in the performance of a task by calculating the extent to which certain skills are identical to their own and by inferring the magnitude of their commitment versus the ability required to produce a comparable result.

Assessment of Personal and Situational Resources: Gist and Mitchell (1992) emphasize that a person's evaluation of private and situational supplies relates to an individual's consideration of personal and situational factors. Personal factors may include such items as skill level, anxiety, motivation and energy available, while situational factors may consist of features, for instance conflicting requests and distractions (Gist and Mitchell 1992).

Self-Efficacy Relationship Model: The four types of factors exercised in the improvement of Self-efficacy are enactive mastery (personal attainments); vicarious experience (modelling), verbal persuasion and physiological arousal (e.g. anxiety) provide specific information clues. Figure 2 illustrates a simplified overview of the four types of factors used in the growth of Self-efficacy and the three categories of assessment relationship procedures of Self-efficacy. The focus is on the judgments and information groups before the efficacy assessment and the consequences of efficacy beliefs, for example, the goals are not the principal interest of Figure 2. The three forms of evaluation methods give the impression that they are involved in forming Self-efficacy. Gist and Mitchell (1992) stress that even though the three evaluation processes are distinct, progression through them may occur repetitively, and the relative importance within each method may be influenced by the complexity of the assignment itself or through the magnitude of previous experience with those of the challenge. The assessment procedures will produce knowledge data that could be used in a summary level decision process that determines Self-efficacy that is orchestration ability estimation (see Figure 2). Bandura (1988) highlights that self-appraisal is a process in which various sources of information are evaluated and integrated to form self-efficacy, and that the comparative valuation of information may differ across domains of functioning and situational environments. 
Figure 2: Self - Efficacy Relationship Model

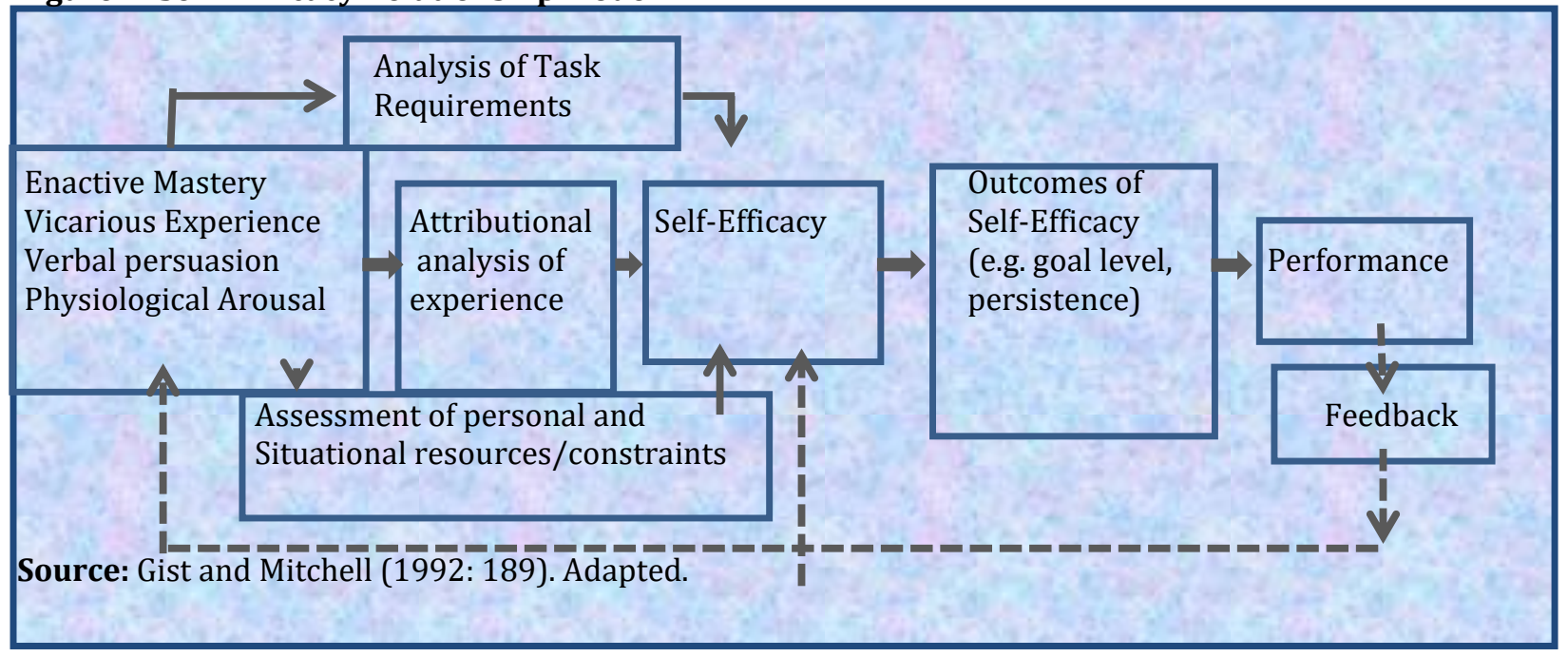

Analysis of Self-Efficacy Assessment Processes and Relationship Model: The theory of Self-efficacy regarding the alignment amongst the four factors for advancing Self-efficacy and the three valuation procedures required to understand Self-efficacy will decide on the level of Self-efficacy that absolutely affects the learner's performance results. In the first two valuation procedures, job prerequisites and attributional assessment of involvement provide the required standards to perform meticulously on a job with an aptitude and motivational factors. The third assessment takes into account the personal and situational components. The assessment processes are a significant tool used in deciding the level of Self-efficacy.

Theoretical/Conceptual Framework: The current study gives rise to the use of empirical data produced from individual interviews used to produce semi-empirical data that do not fall under positivism. In this way, features of both the positivist and post-positivist opinions come into existence. It is likewise imperative to affirm and not to disregard the Critical Theory as its purpose is to build better and fairer situations and an equal opportunity culture in which individuals and combined freedoms are obligatory. For the most part, the disparity in the conceptual frameworks poses the issue of whether a particular form of analysis or more than one approach is utilized to answer the study. The research issue is complicated, together with the survey questions and the associated research goals. For this study, qualitative data were thus favoured. The synthesis of research methods has resulted in this work adopting a realistic stance (Creswell and Plano Clarke, 2011). The reason for supporting a pragmatic research paradigm is that this particular position considered 'as the philosophical partner of mixed-method research', provides a sustainable solution to complicated research challenges and affords a pragmatic, primary point of alignment with post-positivism as well as interpretivism (Johnson, 2004). Figure 3 illustrates the proposed theoretical model underpinning the present study. An in-depth analysis incorporating the study's problem statement and the proposed theoretical model underpinning the current research follows thereafter. 


\section{Figure 3: Proposed Theoretical Model Underpinning the Study}

THEORIES

Rauding Theory

Bloom's Taxonomy

Krathwohl's Taxonomy

Facione Critical Thinking Skills

\section{LEARNER NEEDS}

Remember Rauding

Understand Researching

Apply Planning

Analyse Inference

Evaluate Self-Regulation

Create

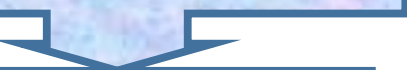

\section{SELF-EFFICACY SOURCES}

Mastery experiences

Modelled Behaviour

Social Persuasion

Physiological Responses

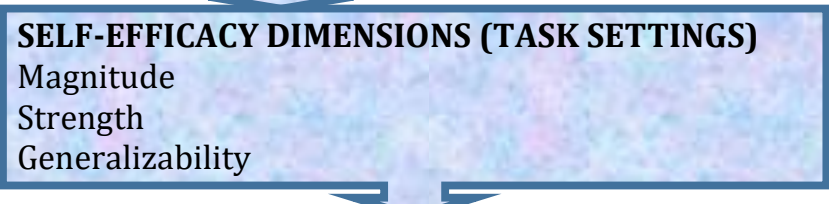

SELF-EFFICACY AND LEARNER PERFORMANCE (OUTCOME)

Cognitive

Motivational

Affective

Selection

\section{SELF-EFFICACY ASSESSMENT PROCESSES (MEASUREMENT)}

Analysis of Task Requirements,

Attributional Analysis of Experience, and

Assessment of Personal and Situational Resources

Source: Self-generated

\section{Methodology}

Research Design: The current research paper made use of a qualitative methodology.

Sampling Design: The target population considered for the current study were all DUT and MUT Management Accounting lecturers.

Sampling Techniques: A census survey was considered to be a more appropriate method and relevant to the present study.

Data Collection Method: Interviews (qualitative method) with lecturers from the Department of Cost and Management Accounting at DUT and MUT were conducted.

Data Analysis: The following techniques were utilized to arrive at the finalization of the qualitative results: Word Clouds, Cluster Analysis, TreeMaps, Word Trees, and Hierarchy Charts. 


\section{Findings and Discussion}

The interpretation of data has been split-up into the following three key themes:

A. Self-efficacy,

B. General Education Skills and

C. Challenges.

Self-Efficacy Theme: Self-efficacy was a primary theme, informed by the following four sub-themes:

- Current Self-efficacy Ability,

- Effectiveness of Communication Skills,

- Self-efficacy vs Academic Performance and

- Other Methods to Improve Self-efficacy.

The discussion on each sub-theme is unpacked below. Figure 4 reflects the cluster analysis of the Self-efficacy theme.

Figure 4: Self-Efficacy Cluster Analysis

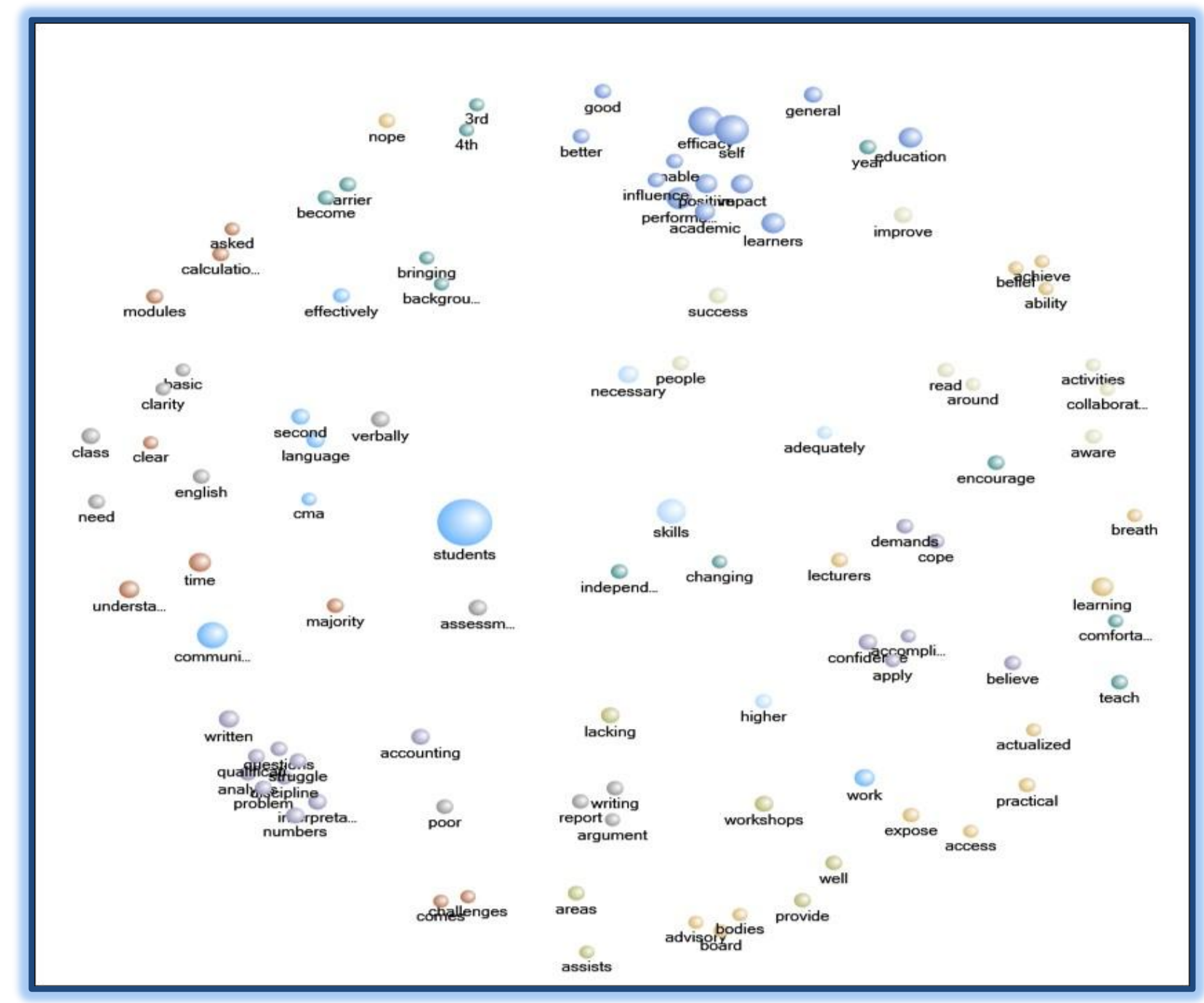

Current Self-Efficacy Ability: The analysis and interpretation of the data regarding the status of Self-efficacy of learners' ability revealed the following results. 
Lack of Self-Efficacy: The majority of respondents believed that learners lacked Self-efficacy, as was determined from the following factors:

Rural Areas: The majority of students came from rural areas with little to no exposure or Self-efficacy abilities.

i. Needs to Be Developed over Time: Self-efficacy needed to be developed over time, and could only be done at the tertiary level.

ii. Dependant on Lecturers: Learners were too dependent on lecturers and lacked their own abilities to learn on their own.

iii. Communication Skills: Learners did not have proper/effective communication skills, which posed a barrier to Self-efficacy abilities

iv. English Vocabulary: Learners were deficient in simple English vocabulary.

Presence of Self Efficacy: No more than $20 \%$ of the respondents believed that there was some degree of Selfefficacy, which was determined from the following:

i. Senior Learners: It was only evident in final year and/or postgraduate learners;

ii. Innate Ability: Some learners had innate abilities to achieve their goals; and

iii. Curriculum Coverage: The curriculum did cover Self-efficacy to some degree.

Effectiveness of Communication Skills: The results of those researchers confirmed the current research findings where most respondents reported that learners lacked effective communication skills in the following ways:

Written Skills: Written communication skills appeared to be poor in learners. One respondent mentioned that especially in the Accounting discipline, written communication is a problem due to it being a numbersbased qualification, which poses a struggle for learners to apply written interpretation. As highlighted by the respondent: L12: "Written communication is a big problem in the Accounting discipline. Because this is a primary number based qualification, learner really struggle with the interpretation and analysis questions".

Senior Learners: It appears that primarily senior learners, such as the $3^{\text {rd }}$ and $4^{\text {th }}$ year as compared to those at lower level learners have more effective communication skills.

Report Writing: Two respondents asserted that report-writing skills are very poor and one respondent described it as pathetic. As highlighted by respondents:

L1: "No they don't. With regards to assessments, their report writing is very poor".

L12: "Students cannot put an argument down in writing and their reporting skills are pathetic".

Language: A majority of the learners are second-language English speakers. This poses a challenge to effective communication skills and their ability to grasp what is being mentioned. This makes lecturers continuously repeat themselves. As highlighted by respondent L5: "CMA students are not able to communicate". "The majority of our students are English second language students".

Interpretation: Two respondents asserted that the interpretation and analysis skills of learners are very poor, especially when it comes to numbers.

Expressive Verbal Skills: The majority of the learners cannot express themselves verbally, except those that went to the more advantaged (Model C) schools. As highlighted by the respondent: L12: "Very difficult for students to express themselves verbally. Students who went to Model C schools find it easier to communicate verbally.

Self-Efficacy vs Academic Performance: The literature review findings of Bandura and others was evident, in the current study findings in the following ways: 
Work Independently: Learners will be able to work independently and know the academic expectations of them in their coursework.

Positive Link between General Education Skills, Self-Efficacy and Performance: Self-efficacy can improve academic performance, as General Education skills would enhance the efficiency and skill levels of learners to be able to manage their academic program. Many respondents were confident that Self-efficacy would enhance academic performance.

Enhance Understanding: Self-efficacy will enhance the understanding capabilities of the learner when it comes to their work and it can improve academic performance.

Confidence: Self-efficacy will contribute to building the confidence levels of learners, which will play a role in improving academic performance. As pointed out by respondents: L2: "Firstly if they have confidence in their lecturers and should always apply the concept in real-life situations and curiosity about cost accounting". L3: "Students lack the confidence to cope with the intellectual demands of the program". L10: "If the learners don't have the confidence to pass, then possibly they would drop out. They have to believe in themselves to be able to accomplish their dreams".

Other Methods to Improve Self-Efficacy: The methods mentioned by respondents to improve the Selfefficacy of learners were highlighted in the followings ways:

\section{Workshops and Programmes}

i. Workshops: Specialised workshops such as communication workshops and work-preparedness workshops could assist in enhancing Self-efficacy in learners; and

ii. Mentorship Programme: One institution did have a mentorship program to assist learners with Selfefficacy.

Teaching, Learning and Research: The methods of improving Self-efficacy when it came to Teaching, Learning and Research included the following:

i. Practical Internship-Experience/WIL: Learners ought to be exposed to practical experience or workintegrated learning (WIL), which will enable learners to see how their knowledge and skills fit into a realworld setting. As pointed out by respondents:

L3: "Perhaps hand-on skills and internships/practical/scenario oriented learning".

L6: "To ensure the knowledge gained is actualized".

L12: "Students can be exposed to Work-integrated learning".

ii. Platforms for Research: There should readily available platforms for research, such as open access labs where learners can practice their research.

iii. Innovation and Creativity in Teaching: There has been a shift in how teaching and learning occur. Therefore, the institution should look at innovative teaching methods that are creative and engaging/interactive for learners. Innovation and Creativity in Teaching can be achieved by the following:

Collaborative Learning: With the above, collaborative learning can improve Self-efficacy. As indicated by a respondent: L3: "Pedagogies such as collaborative learning and inquiry-based activities can also improve Selfefficacy".

Change of Assessment Style: Independent learning must be encouraged and facilitated by changing the style of how lecturers assess learners.

Skills and Abilities: Skills and abilities needed to be developed in the following areas:

Critical Thinking: Learners needed to be developed in critical thinking skills that can support their Selfefficacy.

i. Computer Literacy: Computer literacy skills have to be emphasized and developed. 
ii. Promote More Reading: Learners should be encouraged to read more to gain knowledge, other than that in the classroom. As outlined by the respondent: L2: "Encouraging the culture of reading. More successful people read a lot and are aware of what is happening currently in the economy and the world around".

Motivational Speakers: Using motivational speakers can be of significant value to encouraging learners to build Self-efficacy skills. As indicated by the respondent: L12: "Bringing in experts from second language backgrounds who have now become speakers and writers (people who have overcome the barriers sharing their success stories)".

Monitoring and Evaluation: Monitoring and evaluation can be very important in improving Self-efficacy. It is therefore essential to carry out the following:

i. Monitoring of Progress-General Education Skills: After the implementation of General Education skills, learners' progress needs to be monitored and tracked. This can determine if it is working and contributing to Self-efficacy.

ii. Evaluation of Outcomes: With the above, the evaluation of outcomes for general education skills to determine if they are contributing and this will allow room for improvement.

Advisory Boards: One respondent asserted that advisory boards be created and maintained with industry. As highlighted by the respondent: L9: "Maintain an advisory board with Industry and higher professional bodies".

General Education Skills Theme: General Education skills became another prominent theme of the study. The theme was informed by the following sub-themes:

- Equipped with the necessary General Education skills;

- General Education skills vs academic performance;

- General Education skills vs Self-efficacy; and

- Improvement of General Education skills vs learner performance.

Figure 5 reflects the word cloud analysis for General Education.

Figure 5: General Education Skills Word Cloud Analysis

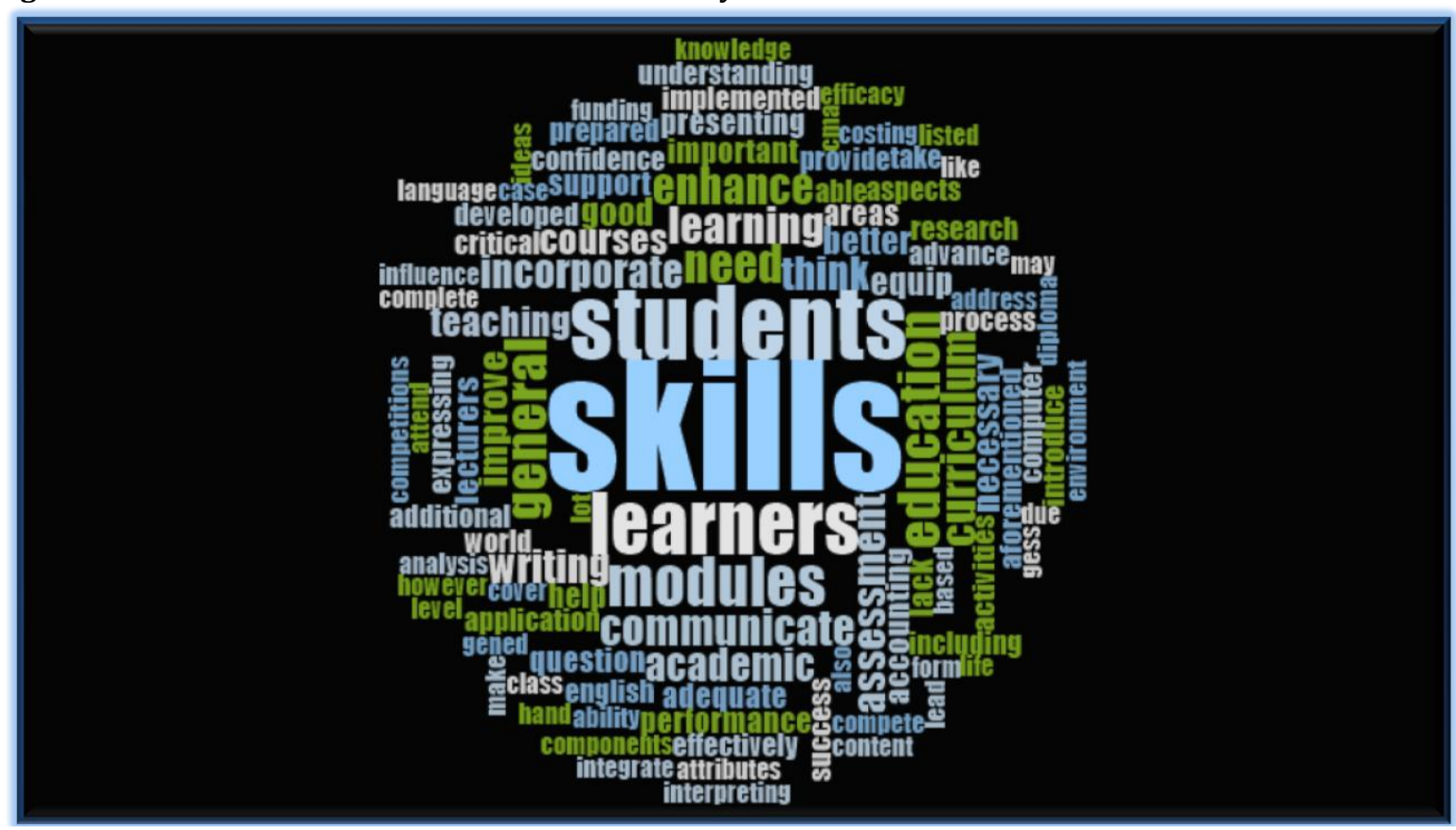


Equipped With the Necessary General Education Skills: The findings of the current study on the aspect of whether learners are currently equipped with General Education skills revealed the following:

Equipped: Only $20 \%$ of respondents believed that learners were equipped. This was attributed to the following:

i. Language Centre: One institution (MUT) had a language center that learners attended 3 times a week.

ii. Computer Lab: One respondent asserted that the institution had a computer lab. It can be interpreted that a computer lab did enhance computer skills.

iii. Community Projects: One respondent indicated that their institution ran community projects such as ENACTUS, which entailed community empowerment activities, requiring learners to have the skills needed to run the project. These skills included the following:

Research: Researching ideas before implementation.

Proposals and Funding: Writing and presenting funding proposals.

Compete Nationally: Learners compete in ENACTUS projects nationally. Hence, they must have skills for this.

Not Equipped: A majority of respondents believed that learners were not equipped with General Education skills, due to the following reasons:

i. Teaching Approach and Methods: Developing General Education skills are dependent on the teaching, learning and assessment strategies of teachers/lecturers. If they are not effective in such, then this will hinder General Education Skills in learners.

ii. Poor Pass Rate: Poor pass rates indicate a lack of General Education skills.

iii. Interpretation: Learners have difficulties in interpreting questions, which implies a lack of General Education skills.

iv. Fearful of Self-Learning: One respondent made an important point that learners are fearful of learning due to them lacking a majority of the General Education skills. One assumes that learners are aware of such skills due to living in the digital age, but they are not.

v. Expressive Writing Skills: Learners cannot express themselves via written skills.

vi. Disadvantaged Backgrounds: Learners who come from disadvantaged backgrounds are the most affected by the lack of General Education skills, which is evident in them.

vii. Difficulties in English: Learners generally struggle with the English language due to it not being their first/home language. Hence, even whilst General Education is available in the curriculum to some degree, learners still battle to learn about it due to their poor proficiency in English.

viii. Curriculum Intervention Needed: More curriculum intervention is crucial to harness and develop General Education skills in learners. As highlighted by respondent L5:

"No, they are not adequately prepared with the necessary general education skills". "The curriculum needs to address these skills, as they are not merely developed by maturation. They are developed with practice".

ix. Computer Literacy: Many learners are not computer literate when they enter the campus, which hinders their progress.

General Education Skill vs Academic Performance: The above sub-theme examines the impact of General Education skills on academic performance. The following was uncovered regarding the impact of General Education skills on academic performance:

Application of Theoretical Knowledge to the Real World: The above was a major factor whereby General Education skills would enable learners to think and apply their theoretical skills to the real-world environment. This becomes a constituent of academic performance combined with practical workability. As expressed by respondents: L3: "Quite germane to their accounting role as numbers have to be transformed to consumables for the end-users".

L5: "The General Education skills have a positive influence on academic performance. It helps with the application of theoretical knowledge of the modules". 
L10: "The skills go hand in hand with the qualification because when the learners get into the workplace they will also need to have these skills".

Holistic Success: General Education skills are important for holistic success, which includes the academic environment, business world and life in general.

Enhance Academic Success: The success of academic modules can get better as learners will ascertain how to cope with modules and the course as a whole. As pointed out by respondents: L11: "They are very important aspects which a learner would need to be successful in their modules and the course as a whole. Lacking one of the skills listed above may impact negatively on a student's academic success". L13: "Teaching learners these skills is important as it helps them cope with their courses better".

Build Confidence and Capacity: General Education skills not only have the potential to enhance academic performance but also contribute towards building confidence in learners. This can promote entrepreneurial capacity in KwaZulu-Natal, especially seeing that they are CMA learners.

Skills for Digitalised Environment: Skills such as report writing, analysis and information evaluation are important, especially in the current digitalized environment. As highlighted by the respondent: L7: "They are very important as we need such skills in writing up reports, analyzing, quantifying and evaluating information which is presented in a digitalized environment".

General Education Skill vs Self-Efficacy: The sub-theme examines the impact of General Education skills on Self-efficacy and the following was uncovered:

Writing Skills: Writing skills would improve through General Education.

Think More Independently: General Education skills would enable learners to think more critically and independently.

Accounting Skills Dependent on General Education Skills: One respondent asserted that the delivery of accounting skills was dependent on General Education skills.

More Competitive: General Education skills will stimulate critical thinking, which also allows learners to become more competitive.

Enhance Teaching and Learning Processes: One respondent made an interesting point, whereby General Education skills would benefit both the teaching and learning process. The learner would be able to understand teaching content better, which would make the teaching process smoother.

Enable Understanding: General Education enables learners to understand their courses and the questions presented to them.

Confidence and Creativity: General Education will promote more confidence and creativity in learners, which could improve their employability options.

Communicate Effectively: Communication skills would get better and it would make learners communicate more effectively.

Application of Knowledge: General Education skills will enhance Self-efficacy when it comes to learners applying knowledge gained at a practical level and in general. As indicated by the respondent: L6: "Yes. I think it will enhance the learners' efficacy. Knowledge and its right application are the needed ingredients to enhance the learner's Self-efficacy as it re-orientates the learners on having a paradigm shift from the norms".

Improvement of General Education Skill vs Learner Performance: The above sub-theme examined how General Education skills can be improved to enhance learners' performance. The respondents highlighted the following: 
Incorporate General Education Skills into Core Curriculum Modules: The majority of respondents indicated the need for integration of General Education skills into the core curriculum. The integration of General Education skills is supported by the following responses from respondents:

L5: "Incorporating general education skills into the core curriculum".

L6: "Incorporate general education skills into the curriculum".

L7: "They should introduce general education in terms of assessment, and it should be incorporated in the modules, not as a standalone. Integrate it within the module".

L9: "Incorporate General Educations skills in the modules/subjects".

L10: "Introduce such skills into the CMA program".

Programs, Courses and Classes: The building on curriculum integration emanated other suggestion of more programs, courses and classes. The suggestions are separated into the following:

i. Short Courses - Elective: Provide short courses. This should be an elective for those learners that may require it and it should be free. This will improve the uptake of the course.

ii. Re-Curriculated Programmes: General Education skills will be a part of the re-curriculated programs and it will serve to address the lack of current skills.

iii. More Workshops: There will be more General Education skills-based workshops hosted.

iv. Language Skills Class: Classes addressing language skills be hosted and learners should attend these at least twice a week.

v. Extra-Curricular Activities: General Education skills can come into being through extra-curricular activities. Respondent L14 made a good point about being more creative in improving General Education skills through creative extra-curricular activities such as games and talent shows.

Learners' Responsibility in Education: One respondent asserted that learners also needed to take responsibility for their education to improve themselves, their families and address societal ills. As corroborated by the following reactions from respondent L9:

"Learners need to take pride in their academic life".

"Strive to better themselves and their families".

"This improves the country's education skills"

"Eradicate unemployment, crime".

Content Analysis of Curriculum: The curriculum needs to be evaluated and analyzed in terms of General Education content, as asserted by respondents. This will enable an improvement of the curriculum. As validated by the respondent: L3: "I should think a solution to this should be based on the content analysis of DUT's curriculum in this area". "Until you review DUT's curriculum contents as suggested in Q5 above as to whether or not it's adequate, then the way forward in terms of improvement can be clearer. In any case, there will always be room for improvements, whether good or bad".

Application of Theory and Practice: As part of General Education, learners need to be exposed to the industry so they can see how their theoretical knowledge will fit into the practical working world. As indicated by respondents: L2: "Yes I believe if we take our learners to these manufacturing industries they will have a better understanding of what we teach them. For instance process costing, job costing systems". L12: "The GE skills will help with the application of theory and the analysis thereof".

Teaching Learning Development Committee Support Unit (TLDC): One institution had a TLDC support unit to support learners and staff on General Education skills. This unit was important when it came to:

i. Prepare Learners For the Workplace: It equipped and prepared learners for the workplace.

ii. Build Learners' Confidence: TLDC built learners' confidence and allowed them to express themselves.

Challenges Theme: Unfortunately, as with many initiatives and innovations, challenges do exist. The theme is, therefore, informed by following the sub-themes:

- Barriers to learners' success and

- Difficulties in the interpretation of questions. 
Figure 6 illustrates a word cloud analysis of challenges to learners' success in Cost and Management Accounting.

Figure 6: Word Cloud Analysis of Challenges

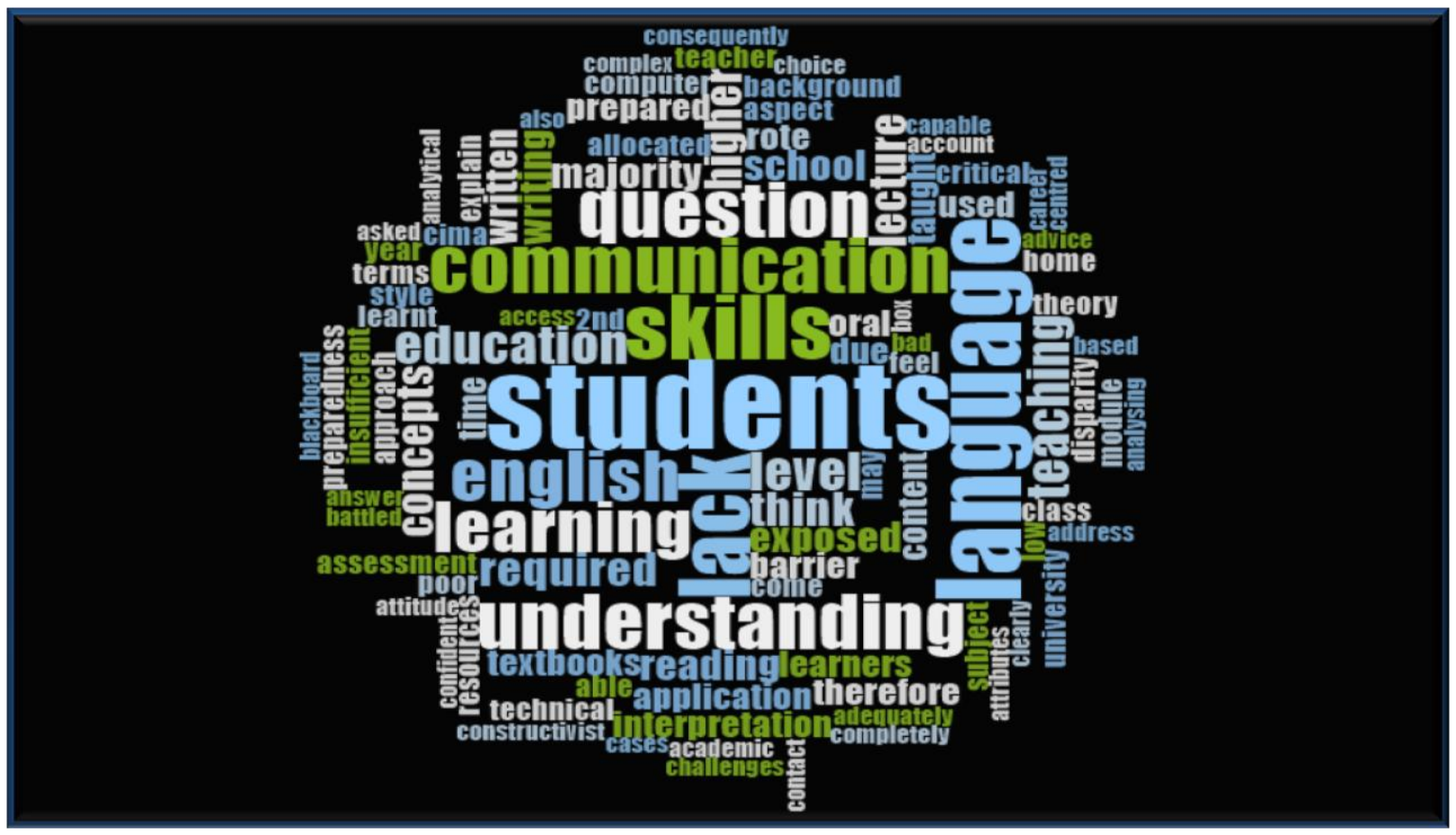

Barriers to Learners' Success: The barriers to learners' success in Cost and Management Accounting included the following:

Teacher and Learning-Centred Barriers: It was important to note that 'teacher and teaching' related barriers to learners' success surfaced from the results. These were:

i. Time for Teaching and Learning: Module time of 4 hours per week can be insufficient for deep learning and the application of theory to practice. As validated by the respondent:

L12 "Allocation of time/periods for learning and teaching and assessment. Most modules have 4 hours per week, but I feel that more time should be allocated for deep learning and the application of theory to take place".

ii. Teaching Approach and Methods: The current teacher-based approach and methods of teaching need to be improved. There need to be more constructive and creative approaches. Furthermore, interactive elearning approaches are required and the current Blackboard e-Learning systems are ineffective. As indicated by the respondents:

L5: "The emphasis is on a teacher-centered approach as opposed to a constructivist approach school level."

L12: "Lecture-based teaching. Blackboard is purely a repository for content".

L12: "The notional hours and contact hours are not explicit for the learners".

L12: "A variety of teaching methods and learning styles should be taken into account".

L13: "Some lecturers do not explain concepts clearly enough".

L14: "Teaching style".

i. Teacher Confidence Levels: Lecturers are also not confident in teaching due to their own levels of education, which makes it difficult for learners to understand their courses.

ii. Lack of Competent Teachers/Lecturers: In light of the low level of teacher education, this adds to inexperienced lecturers who cannot teach well. Silo Teaching: There seems to be a silo effect of teaching within the department. 
iii. Lack of Assessments towards Creativity: Learners needed to be stimulated to think and learn creatively, however currently, there is a lack of assessments from lecturers that require learners to think critically and creatively.

iv. Lack of Application: Lack of application to concepts and formulae taught could also be stemming from teachers' lack of ability to show such application.

v. Integration- Foundation vs Higher Level: One respondent made a key point that there was a lack of integration of content between the foundation and higher-level subjects. It means that more integration is required so learners can see the trajectory of how their foundation skills play a role as they transit to higher levels of study.

Social-Environmental-Attitudinal Factors: The results mentioned below are summarised and emanate, as they were interrelated:

i. Attitude towards Learning: Attitude towards learning is low amongst learners.

ii. Career Choice: Some students were in the wrong career and therefore experiencing challenges.

iii. Environmental Factors: The university environment and university infrastructure seem to be posing challenges to learners.

iv. Thinking at a Higher Level: Learners do not seem to be exposed to critical thinking and higher levels of thinking, considering that they are in higher education.

v. Maturity: (no real explanation was given, but perhaps this can be related to low levels of maturity amongst learners).

vi. The disparity in S.A Education System: Learners' under-preparedness was associated primarily with the disparity in the South African education system. This relates to learners from poverty and disadvantaged backgrounds that went to disadvantaged schools. As highlighted by respondents:

L5: "The disparity in the SA education system is a major barrier as the majority of our learners come from a disadvantaged educational background. Consequently, the majority of our learners are inadequately prepared for higher education".

L5: "Disparity related to quintile ranking".

L14: "School background".

L14: "Poverty".

vii. Transition- High School to Tertiary: Learners did not seem to have mentality transitioned from the schooling level to the higher education level.

viii. Time Management: There was no real explanation given, but perhaps this can be associated with the poor time management skills of learners.

ix. Language - This was the main barrier as most learners were not first language English speakers.

Skills and Literacy: The learners were lacking/under-developed in the areas themselves, which became barriers to success, as evidenced by the findings below:

i. Communication Skills - Oral and Written: A number of respondents ranked oral and written communication skills as severely lacking, especially for students at a higher education level. As highlighted by respondents:

L5: "Under preparedness for higher education in respect of graduate attributes such as communication skills in oral and written persuasion".

L6: "Lacking communication skills (Reading, writing and understanding)".

L11: "Lack of communication skills".

L12: "Written and oral communication skills".

ii. Reading and Writing Skills: Learners lacked the academic reading and writing skills.

iii. Numerical Skills: There was a deficiency in numerical skills amongst learners.

iv. Mathematical Literacy: A deficiency in Mathematical Literacy was noted.

v. Computer Skills: Learners lacked proficiency in computers due to minimal to no exposure. As highlighted by the respondent: L10: "Students are not proficient in computers. They are not exposed to any form of P.C. yet are required to know all aspects of a P.C". 
Resources: There is a lack of/barriers in terms of resources that hinder learner success, which include: i. Lecture Rooms: lecture rooms are crowded.

ii. Finance: (no real explanation given, but perhaps this can be related to learners' financial situation). iii. Educational Resources: There seems to be a lack of educational resources for learners. The following were noted:

Textbooks and Stationery: There seems to be a lack of textbooks and stationery. When it came to textbooks, there was a lack of textbooks that were CIMA orientated. As highlighted by respondents: L3: "Insufficient textbooks that explain CIMA principles". L4: "Insufficient questions (from CIMA textbooks) by lecturers for use as class practice questions".

Quality of Study Materials: The overall quality of study material was poor which posed a barrier to learners' success.

Access to Computers and Facilities: Students have limited access to computers and printing facilities.

Lack of Understanding and Interpretation: Learners lack the ability to understand what is required from them at a higher education level, as well as the complex concepts of their modules.

Industrial Non-Familiarity: Students are not familiar with the industry environment related to the applicability of their studies.

Difficulties- Interpretation of Questions: Similar to barriers, it was important to establish the factors that cause difficulties when it came to learners interpreting questions posed in class. These factors included:

Language: As previously emphasized, language remains a primary difficulty. It relates to the following:

English Not First Language: Students struggle with interpreting and analyzing questions due to English not being their first/home language.

Technical Language: Learners do not understand technical subject language as well, which hinders their progress.

Communication Skills: As emphasized, learners lack communication skills, especially at the first-year/entrylevel. Furthermore, it is perceived that the communication module at the first-year level is too generic and basic and does not address the problems with written and oral communication skills.

Rote-Learning: Learners stick to memorizing and/or by rote-learning due to a lack of understanding of questions. Rote-learning at the tertiary level is not recommended, especially for practical subjects.

Differentiating Skills: Learners lack the skill of differentiating key points from the questions asked.

Interpretation and Analytical Skills: Learners lack the ability to interpret questions. Furthermore compounding the issue is the fact that the learners are not familiar with the basics of the English language. Learners do not understand terms and synonyms used in examples. As highlighted by the respondents: L12: "The terms in the questions may be synonyms of the terms used in class, but because of communication barriers, they are lost. They then feel that it is concepts that were not taught". L14: "Students lack analytical skills when reading and interpreting the questions".

\section{Conclusion and Recommendations}

Results imply that there is currently a severe lack of General Education skills in the current learners, which needs attention. The results further imply that General Education skills can have a positive impact on academic performance, as per the factors listed. It can also have a positive impact on Self-efficacy (as per factors shown). Similar to General Education skills, when it came to Self-efficacy, there is also a lack of such in 
current learners. Communication skills seem to be very poor amongst current learners, which needs addressing because respondents believe that Self-efficacy can have a positive effect on the academic performance of learners.

Recommendation: There is room for improvement for general education skills that can enhance learner, performance. Hence, the main strategy would be to incorporate General Education skills into the curriculum. The methods in improving Self-efficacy should revolve around innovative teaching, learning and research methods; increasing skills development such as critical thinking and computer skills; and promoting more Self-efficacy based workshops and programs, amongst the other factors shown.

\section{References}

Angba, A. O., Adesope, O. M. \& Aboh, C. L. (2009). Effects of socio-economic characteristics of rural youths on their attitudes towards participation in community development projects. International NGO Journal, $4(8), 348-351$.

Bandura, A. (1988). Reflection on non-ability determinants of competence. In: Sternberg, R. J. and Kolligian, J. Jr. Eds. Competence considered: perceptions of competence and incompetence across the lifespan. New Haven: Yale University Press, 315-362.

Bandura, A. (1994). Self-Efficacy. In: Ramachandran. V. S. eds. Encyclopaedia of human. New York: Academic Press, 71-81.

Bourke, B., Bray N. J. \& Horton, C. C. (2009). Approaches to the core curriculum: an exploratory analysis of top liberal arts and doctoral-granting institutions. General Education, 58(4), 219-240.

Cherry, K. (2018). What is Self-Efficacy? Available: https://www.verywell.com/what-is-Self-efficacy-2795954 (Accessed 26 September 2018).

Corrigan, T. (2009). Socio-economic problems facing Africa: insights from six APRM country review reports. Available: http://www.saiia.org.za/occasional-papers/socio-economic-problems-facing-africainsights-from-six-aprm-country-review-reports (Accessed 26 September 2016).

Creswell, J. W. \& Plano Clarke, V. L. (2011). Designing and conducting mixed research methods. Thousand Oaks, California: SAGE Publications.

Gist, M. E. \& Mitchell, T. R. (1992). Self-Efficacy: a theoretical analysis of its determinants and malleability. Academy of Management Review, 17(2), 183-211.

Greer, H. V. (2012). DUT curriculum glossary (unpublished policy document).

Guba, E. G. \& Lincoln, Y. S. (1994). Competing paradigms in qualitative research. In: Denzin, N. K. and Lincoln Y. S. eds. Handbook of qualitative research. London: SAGE Publications, 105-117.

Hanushek, E. A. \& Woessman, L. (2007). The role of education quality for economic growth. Policy Research Working Paper 02/2007. World Bank.

Imoh, A. N., U-James, I. \& Nwachukwu, E. O. (2009). Comparative analysis of poverty status of community participation in rural development projects of Akwa Ibom State, Nigeria. New York Science Journal, $2(6), 68-75$.

Johnson, P. L. (2004). Mixed methods, mixed methodology health services research in practice. Qualitative Health Research, 14 (2), 259-279.

Kiani, A. K. (2015). The role of education on economic growth in Pakistan. Available: https://www.researchgate.net/publication/228921856_The_Role_of_Education_On_Economic_Grow th_in_Pakistan (Accessed 27 September 2018).

Kift, S. (2008). 21st Century climate for change: curriculum design for quality learning engagement in law. Available: http://www.austlii.edu.au/au/journals/LegEdRev/2008/2.html (Accessed 27 September 2018).

Krathwohl, D. (2002). A revision of Bloom's taxonomy: an overview. Theory into Practise, 41(4), 212-225.

Landy, B. (2012). Graph: For high-scoring learners, socioeconomic status still matters. Available: https://tcf.org/content/commentary/graph-for-high-scoring-learners-socioeconomic-status-stillmatters/ Accessed 20 July 2018).

Oladipo, F. O. \& Adekunle, O. A. (2010). Empirical determination of socio-economic status and its relationship with selected characteristics of rural male farmers in Kwara State, Nigeria. Agriculture and Biological Sciences, 6(1), 64-76.

Ormrod, J. E. (2008). Human learning. $5^{\text {th }}$ ed. Upper Saddle River, New Jersey: Pearson Education. 
Ramos, J. T. (2010). A study on schema activation, summarizing, and critical evaluation as predictors of writing proficiency. Research and Review, 5(1), 31-39.

Siegle, D. (2000). An introduction to self-efficacy. Available: http://nrcgt.uconn.edu/underachievement_study/self-efficacy/se_section1/ (Accessed 29 September 2018).

Taylor, N. (2009). The state of South African schools Part 1: Time and the regulation of consciousness. Education, 46, 9-32.

Taylor, N., Van der Berg, S. \& Mabogoane, T. (2012). What makes schools effective? Report of the national schools effectiveness study. Cape Town: Pearson Education South Africa.

Taylor, S. \& Yu, D. (2009). The importance of socioeconomic status in determining educational achievement in South Africa. Stellenbosch Economic Working papers: 01/09. Stellenbosch University: Department of Economics and Bureau for Economic Research.

University of Central Arkansas. (2018). Objectives for the skills. Available: https://uca.edu/core/objectivesfor-the-skills/ (Accessed 30 September 2018).

University of South Africa. (2012). How does socio-economic status impact educational outcomes in South Africa? Available: http://www.unisa.ac.za/cedu/news/index.php/2012/09/how-does-socioeconomic-status-impact-on-educational-outcomes-in-south-africa/ (Accessed 30 September 2018).

Wall, L. J., Pettibone, T. J. \& Kesley, K. D. (2005). The impact of socio-economic status on leadership potential in an agricultural leadership program. Southern Agricultural Education Research, 55(1), 153-161.

Washington State University. (2019). Aims of general education. Available: http://gened.wsu.edu/overview/atWSU/ (Accessed 03 October 2019).

Zimmerman, B. J. (2000). Self-Efficacy: an essential motive to learn. Contemporary Educational Psychology, 25, 82-91. 